\title{
Article \\ Detection of Single Burials Using Multispectral Drone Data: Three Case Studies
}

\author{
Benjamin Rocke *(D) and Alastair Ruffell
}

check for

updates

Citation: Rocke, B.; Ruffell, A.

Detection of Single Burials Using Multispectral Drone Data: Three Case Studies. Forensic Sci. 2022, 2 , 72-87. https://doi.org/10.3390/ forensicsci2010006

Academic Editors: Francisca Alves Cardoso, Rosa Maria Di Maggio,

Pier Matteo Barone and

Laurance Donnelly

Received: 18 December 2021

Accepted: 7 January 2022

Published: 18 January 2022

Publisher's Note: MDPI stays neutral with regard to jurisdictional claims in published maps and institutional affiliations.

Copyright: (C) 2022 by the authors. Licensee MDPI, Basel, Switzerland. This article is an open access article distributed under the terms and conditions of the Creative Commons Attribution (CC BY) license (https:// creativecommons.org/licenses/by/ $4.0 /)$.

\author{
School of Natural and Built Environment, Queen's University, University Road, Belfast BT7 1NN, UK; \\ a.ruffell@qub.ac.uk \\ * Correspondence: brocke01@qub.ac.uk
}

\begin{abstract}
Natural burials are interments where a body is buried without embalming fluids or coffins. These burial grounds are ideal locations for retrospective multispectral analysis of non-conventional single burials as the age and location of each grave is documented. The detection of disturbed soil under the influence of human decomposition has been well-studied, but lacks the temporal component needed for characterising simulated clandestine burials. A critical gap in the literature is how these burials re-vegetate and to what extent soil profiles re-establish over years or decades. Multispectral drone data from three natural burial sites in southern U.K. are documented here, with trends in re-vegetation from bare soil to full recovery in graves as old as 2005. As with many burial detection techniques, environmental influence is a limiting variable to universal use of this method. However, we suggest a timeline over which single burial sites in this location reach detection limits and possible reasons for variations in these limits.
\end{abstract}

Keywords: remote sensing; forensics; UAV's; multispectral data; clandestine graves; natural burials; single burials; NDVI; human decomposition

\section{Introduction \\ 1.1. Literature Review}

The use of remote sensing to locate clandestine burials ('burials' in this paper may not necessarily refer to a human body, but imply forensic relevance, while 'graves' are used to indicate interment of a body) is a well-documented area within forensic science. As early as 2002, a retrospective study of a mass grave in Guatemala was detected by the ASTER satellite using multispectral data at $15 \mathrm{~m} /$ pixel resolution [1]. Four years later, Kalacska and Bell [2] simulated a Guatemalan mass grave using multiple larger-scale cattle burials $(5 \mathrm{~m} \times 5 \mathrm{~m})$, which successfully identified against surrounding vegetation by airborne hyperspectral data at a resolution of 3-4 m/pixel.

The resolution of satellite data has been a limiting factor in detecting smaller burials. Single burials could only be detected using sensors mounted to aircraft, such as in Leblanc et al. [3]. As drone (also known as Unmanned Aerial Vehicles or UAV's) technology advanced, sensors previously relegated to satellites or aircraft became accessible at a much lower altitude, image resolution increased drastically [4,5], and single grave burials became the next subject of research.

With the availability of commercial-grade drones, initial studies used off-the-shelf RGB cameras [4] or modified RGB cameras such as those used in Evers and Masters [6]. As drone-mounted multi- and hyperspectral sensors became available, a diverse range of studies over single and mass burials ensued: Urbanova et al. [7]; Butters et al. [8]; Evers and Masters [6]; Brabazon et al. [9]; Murray et al. [10]; Dozal et al. [11]; and Silvan-Cardenas [12]. Many of these studies involved simulated graves using pigs or cattle, which were monitored over months or years, which is common practice in taphonomy [11,12].

The need for a study focussing on the temporal aspect of single human grave detection over multiple years is the inspiration for this work. Rocke et al. [13] successfully imaged a 
16-year-old simulated neonate burial using an NDVI algorithm derived from a standard RGB drone, but this only illuminates the gap between the shorter-term simulated grave studies and older burials. A comprehensive study using multispectral data on many single burials from a range of ages is needed to determine trends in ground disturbances, from burial inception (bare soil) to full re-vegetation.

More sophisticated technology such as hyperspectral data is being used for single or multi-grave detection, most recently by Silván-Cárdenas et al. [12]. While the potential of hyperspectral data to detect anomalies in soil and vegetation is considerably greater than multispectral imaging, hyperspectral data often requires complex computation and algorithms, which is outside the remit of many scientists, humanitarian organisations and law enforcement [14]. The nature and quantity of such data have become so vast, in the shadow of this progress, many unexplored tests remain in more accessible hardware, such as multispectral sensing used here. This study focuses on multispectral data taken at three anonymised natural burial grounds in the UK with interments ranging from 2005-2021.

In addition, we want to highlight how the full potential of this technology can detect single graves, namely in combining multispectral data with digital terrain modelling. This technique extends the application of this work into micro-topography of ground disturbances, which can outlast anomalies associated with vegetation.

\subsection{Site Descriptions}

Site 1 is a flat (relief of $\sim 4 \mathrm{~m}$ ) grassland. The soil characteristics are recorded in Table 1 . At this site, early (2006) burials were at $1.8 \mathrm{~m}$ depth but were later changed to $1.4 \mathrm{~m}$. In the grave digging process, turf is scraped off and replaced, soil is compacted after burial, and early sites were planted with trees around the time of burial. The graves themselves are not mown, but paths between are. No grass seeding is done-the ground re-vegetates naturally. Grasses (see Figure 1), reach about $70 \mathrm{~cm}$ in height except for mown paths. Grass varieties and soil type are listed in Table 1.

Table 1. Summary of site chacteristics.

\begin{tabular}{cccc}
\hline & Site 1 & Site 2 & Site 3 \\
\hline Soil Type & Luvisol & Stagnosol & Luvisol \\
Fertility & Moderate to high & Moderate & Low \\
Drainage & Slightly impeded & Impeded & Freely draining \\
Burial Depth & $1.8-1.4 \mathrm{~m}$ & $1.4 \mathrm{~m}$ & $1.4 \mathrm{~m}$ \\
Site Maintenance & Trimmed regularly & Mown yearly & Mown yearly \\
Burial Ages & $2010-2021$ & $2014-2021$ & $2005-2021$ \\
Grass Type & Cocks Foot, Yorkshire Fog, False Oat, Creeping Bent \\
Grass Height & $70 \mathrm{~cm}$ & $1 \mathrm{~m}$ & $1 \mathrm{~m}$ \\
Relief & $4 \mathrm{~m}$ & $4 \mathrm{~m}$ & $35 \mathrm{~m}$ \\
\hline
\end{tabular}

Site 2 is a flat (relief of $\sim 4 \mathrm{~m}$ ) grassland. Soil characteristics and grass types are recorded in Table 1. At this site, burials are typically $1.4 \mathrm{~m}$ depth. Turf is scraped off and replaced over burials, and soil is compacted after burial and no grass seeding done. Grasses reached one metre in height across the site except for mown paths.

Site 3 is a grassland with much higher relief than previous sites. At this site, turf is scraped the most carefully of the three sites, soil is compacted, and turf replaced. No grass seeing is done. Burial depth here is around $1.4 \mathrm{~m}$ depth. Grass varieties and soil types are listed in Table 1. Grasses reached one metre in height across the site except for mown paths. 


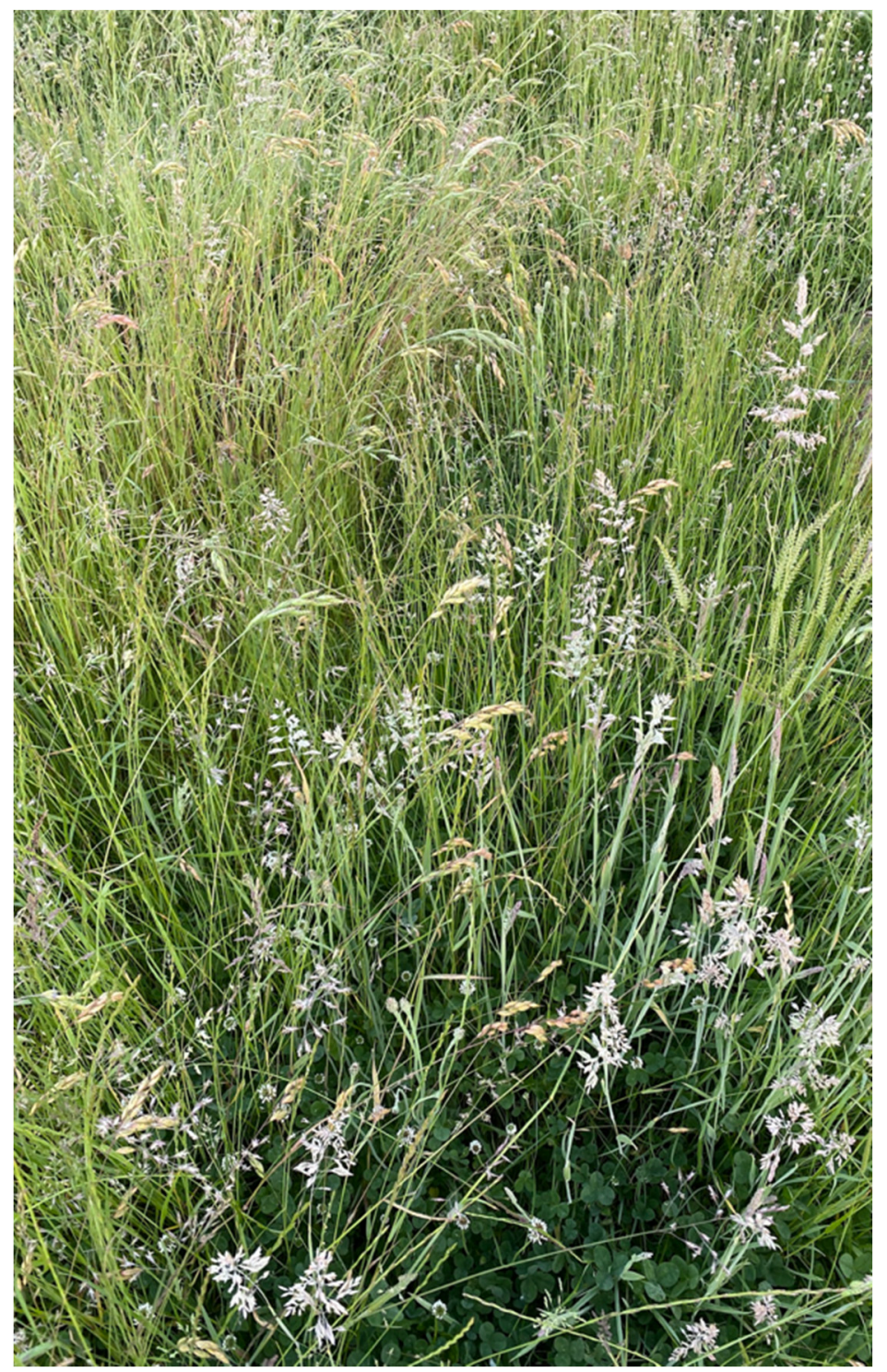

Figure 1. Typical grasses from Site 1, but representative of grasses at all sites. Varieties identified are Cocks Foot (Dactylis glomerata), Yorkshire Fog (Holcus lanatus), False Oat (Arrhenatherum elatius), and Creeping Bent (Agrostis stolonifera). Grass height here is about $70 \mathrm{~cm}$, but grass at Sites 2 and 3 was taller $(\sim 1 \mathrm{~m})$.

\section{Materials and Methods}

\subsection{Data Acquisition}

All three study sites were flown with a DJI Inspire 2-mounted Sentera 6x multispectral sensor in June 2021. Acquisition took place near solar noon at around 13:00 when the sun reached its azimuth (apex of $62^{\circ}$ ). All United Kingdom Civil Aviation Authority and military flight paths and perimeters were checked using the DJI flight safety software updates; a full safety check of the drone and surroundings performed, as per the operator's pilot license and permission granted by the site owners and managers. In addition, visitors were notified in advance of the flights and times, with static notices positioned at visible access points. The Sentera $6 x$ was flown at $90^{\circ}$ facing directly down as this was the only possible configuration for the device. Each site was flown in North/South transects at $60 \mathrm{~m}$ altitude with $80 \%$ front and side overlap. This is higher than recommended overlap from either of the common autonomous flight software packages available: Drone Deploy [15] or Pix4D [16], but the GPS trigger on the Sentera was set to $80 \%$ overlap as a default, and flight patterns reflected this setting. Before each flight, several exposures of the Sentera 
calibration panel were taken. If cloudy weather made take-off and landing light appreciably different, post-flight exposures were also taken. Fortunately, each site was flown in near full sun and only once required post-flight calibration.

The Sentera 6x sensor recorded all five bands and RGB simultaneously at each of the three sites. The sensor has five 3.2MP multispectral bands and one 20MP RGB camera. See Figure 2 for the wavelengths and widths of each of the five bands.

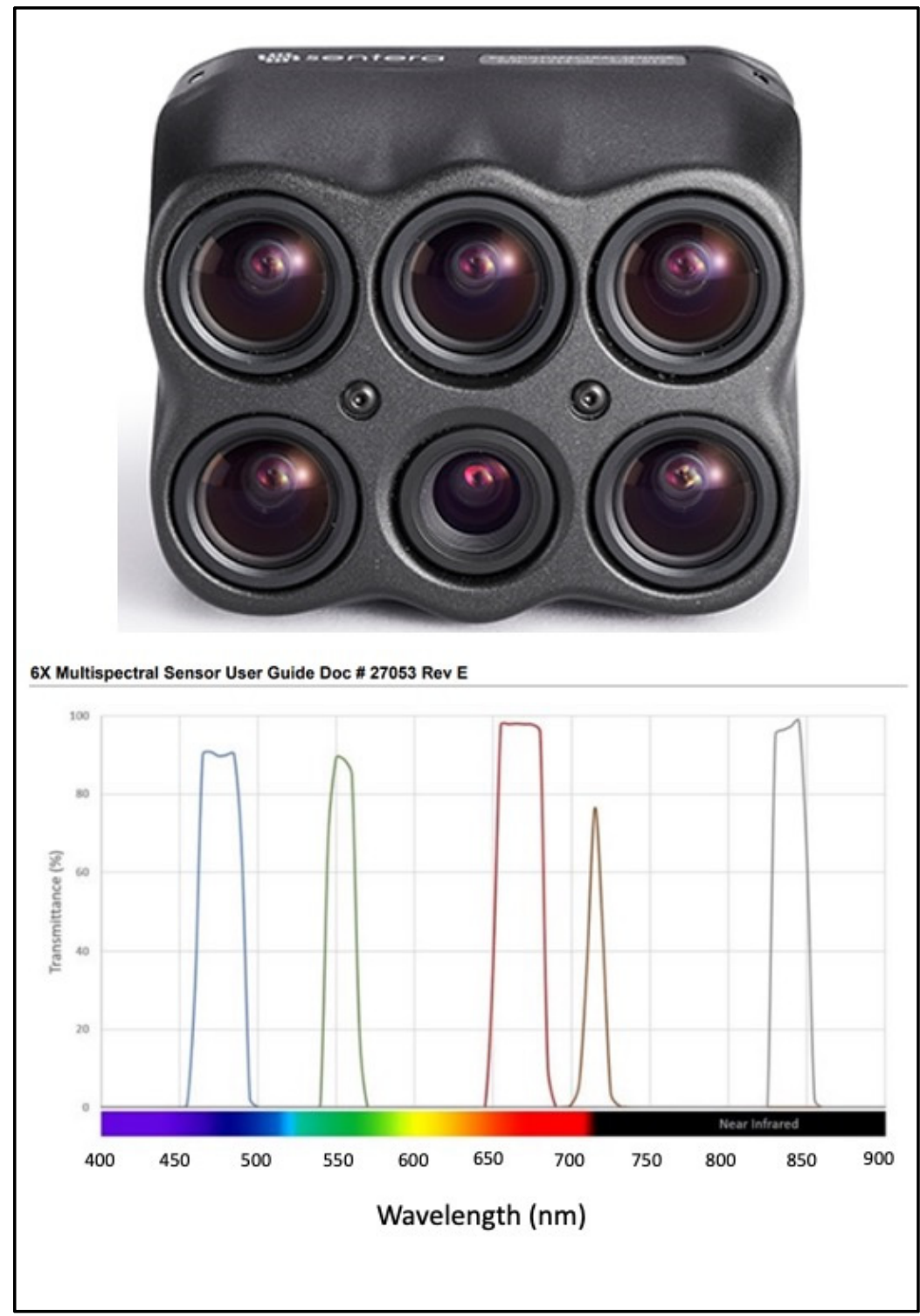

Figure 2. Sentera 6x sensor (taken from https://support.sentera.com/ (accessed on 29 October 2020) with five wavelengths and widths. The 5 bands are: (1) Blue: $475 \mathrm{~nm} \times 30 \mathrm{~nm}$; (2) Green: $550 \mathrm{~nm} \times 20 \mathrm{~nm}$; (3) Red: $670 \mathrm{~nm} \times 30 \mathrm{~nm}$; (4) Red Edge: $715 \mathrm{~nm} \times 10 \mathrm{~nm}$; and (5) NIR: $840 \mathrm{~nm} \times 20 \mathrm{~nm}$. The sixth sensor is an RGB camera.

\subsection{Data Processing}

Multispectral data were loaded into Pix4D Fields, where each of the five bands from the Sentera 6x was photo-stitched into a multispectral orthomosaic (Figure 3). This software automatically recognises the Sentera calibration panel and makes the necessary adjustments. From these orthomosaics, index products can be calculated in the Fields software menu, in this case, VARI (visible atmospherically resistant index), NDRE (normalised difference red edge), NDVI (normalised difference vegetation index), and GNDVI (green normalised difference vegetation index). The calculations for each are shown in Appendix A. 

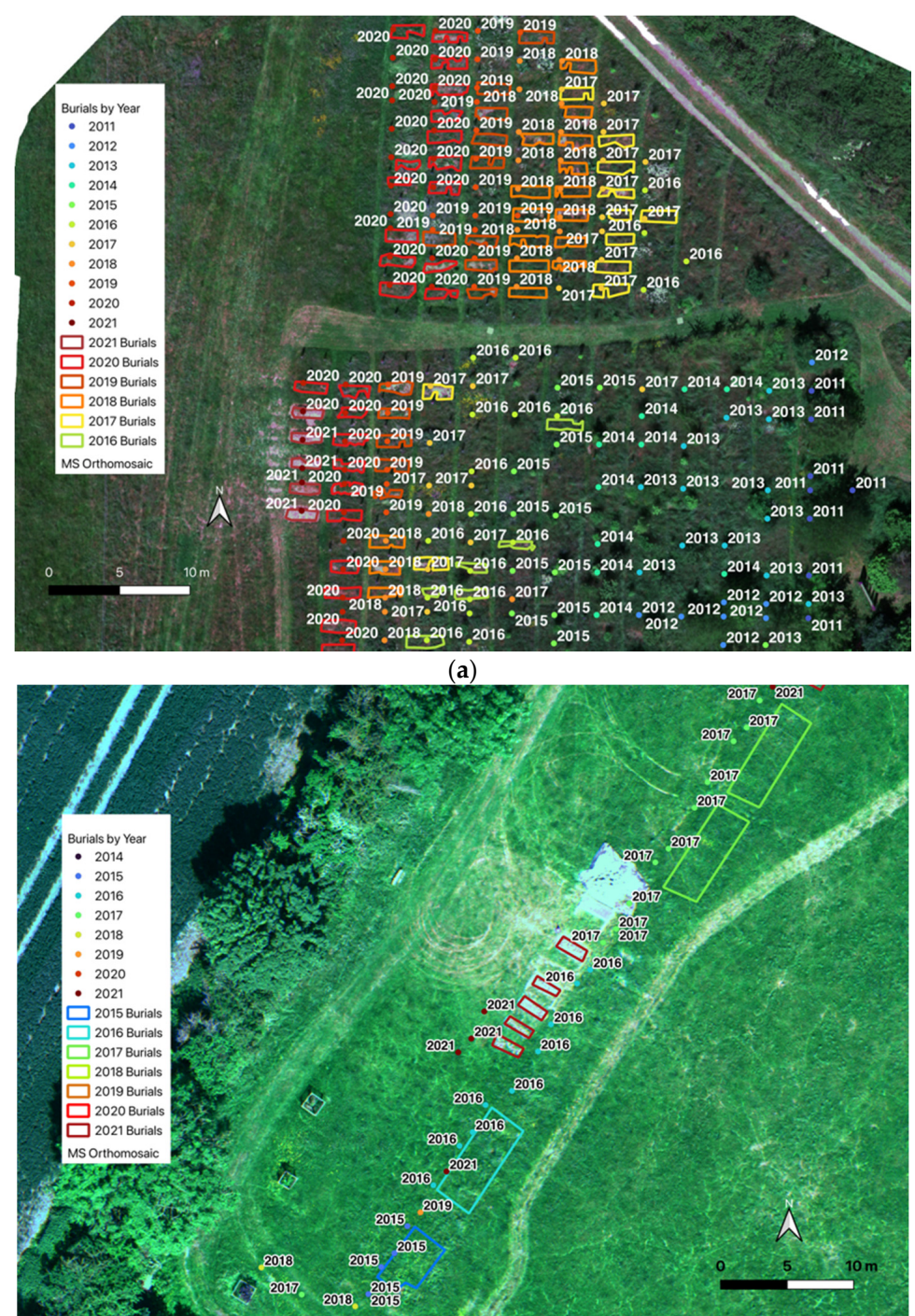

(b)

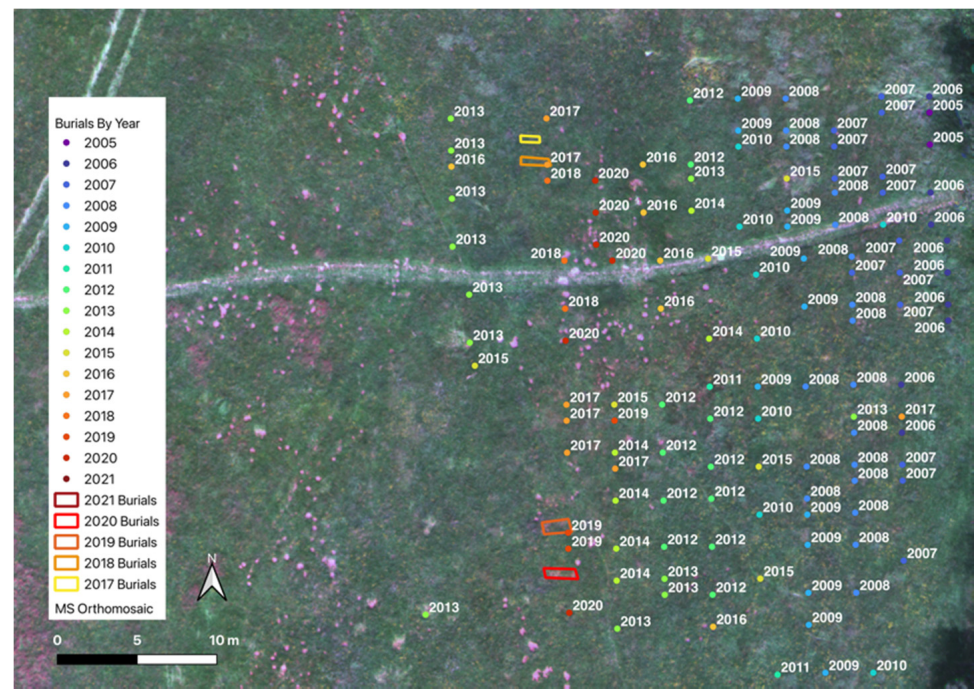

(c)

Figure 3. Sites 1 (a), 2 (b) and 3 (c) multispectral orthomosaics. Red, green, blue, red edge, and near-infrared orthmosiacs are all combined to create these multispectral images. Grave polygons and years associated with them are shown at all three sites. Grave markers are imprecise and had to be corrected visually by either bulk shifts or process of elimination. 
Where visible and corresponding to a GPS grave marker, individual graves were traced on these maps. Grave polygons weren't automatically chosen by each marker because of imprecision of GPS coordinates and the interference of trees, shadow, wildflowers, animal burrows, etc. Rows of graves were traced as groups when clearly delineated and uninterrupted by interference. They were outlined as a group because spaces between the graves became difficult to delineate as graves aged, but an index anomaly was present. This was the case primarily in graves older than six years at Site 1, four years at Site 2, and three years at Site 3 . Where GPS coordinates showed a grave, but no anomaly was apparent in the index map, no polygons were made as imprecision in this data made choosing a precise burial location impossible.

A control site was chosen as a point of comparison for grave polygons at each location at least $1 \mathrm{~m}$ away from graves and possible influences from burials. Each control site was as visually similar (vegetation, slope, aspect) to the grave area as possible (similar vegetation, slope, etc.), but in undisturbed ground.

Control site and grave polygons were all overlain in QGIS 3.20.2. Red and NIR orthomosaics and data points were extracted from them in .csv format in Eigenvector's Solo 9.0 software. Because of the sharp change in reflectance from vegetation between red and NIR bands [17], scatter plots help visualise trends as new burial sites of bare soil vegetate over time. Each grave year .csv data is a series on the scatter plot, and the average NDVI value for each series is plotted as a data label.

Single grave polygons, visible in either digital terrain models (Figure 4), or vegetation indices such as NDVI shown in Figure 5, were tallied to determine the percentage of graves successfully identified. Burials were counted if grave markers corresponded to an anomaly with the appropriate geometry and aren't attributable to other factors such as burrows, wildflowers, trees, shadow, or grass cutting.

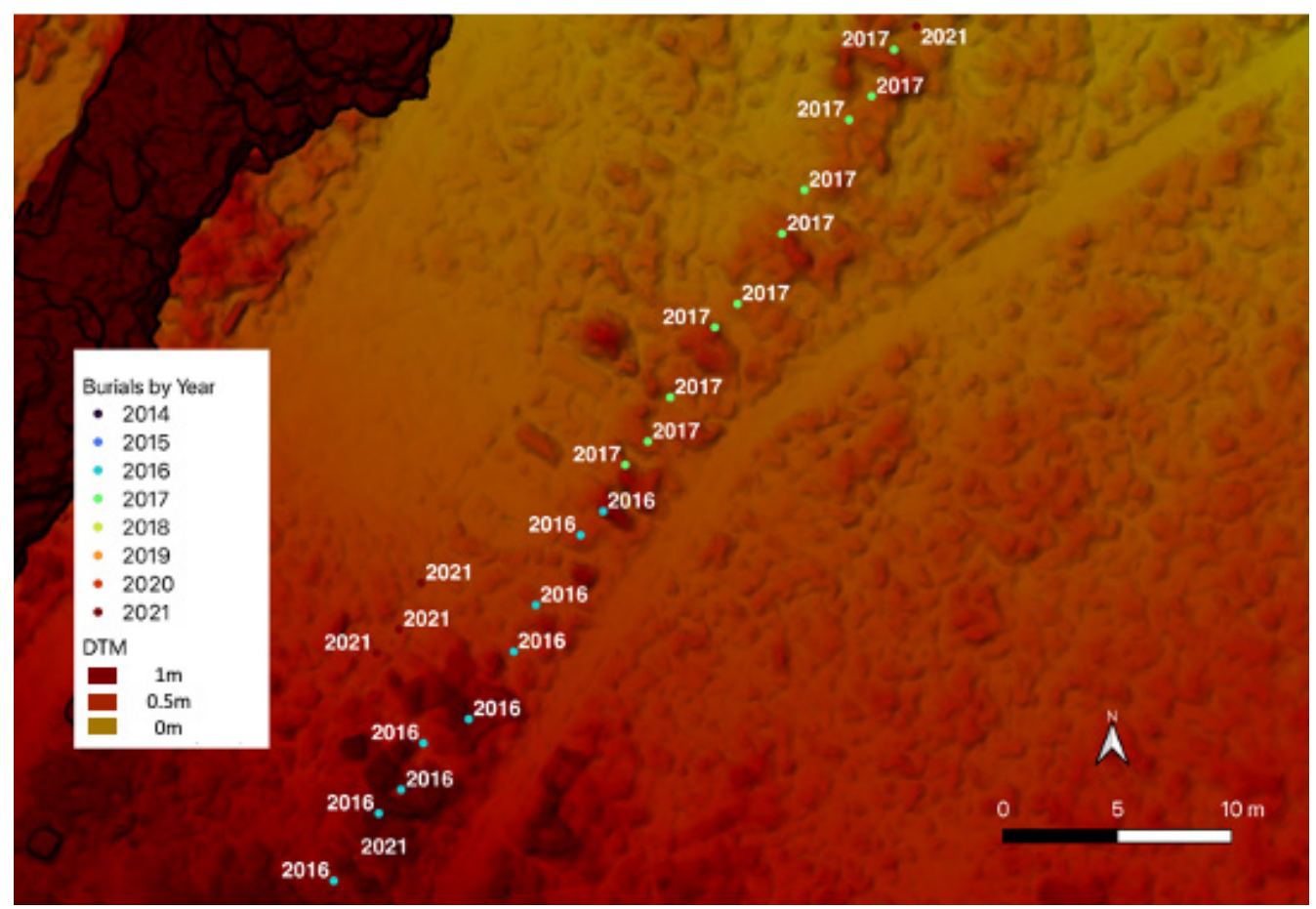

Figure 4. Site 2 digital terrain model showing localised elevation anomalies of gravesites. Relief over single graves is about $30 \mathrm{~cm}$. Z error is $\pm 73 \mathrm{~cm}$. 


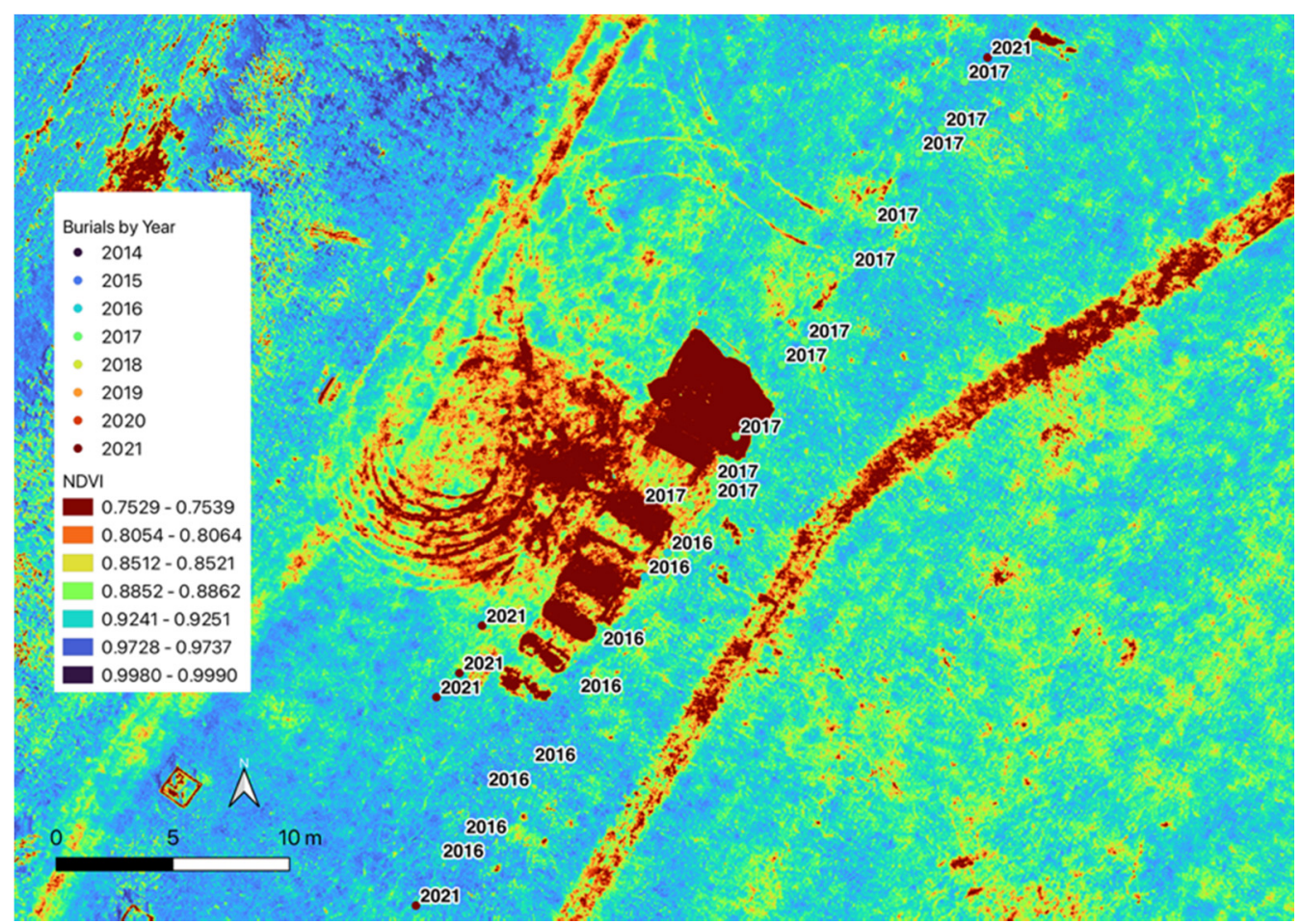

Figure 5. Site 2 NDVI zoom of the same area shown in Figure 4. Graves to the northeast corner from 2017 are imaged more clearly in the digital terrain model. The full range of index values is constrained to highlight localised differences.

\section{Results}

\subsection{Scatter Plots}

Scatter plots consist of point clouds of Red and NIR .csv data from single grave polygons or groups of graves from individual years. Each burial year series is plotted against soil (representing no vegetative recovery) and a control area representing 'full recovery' (the most mature grassland observed from height and diversity), as compared to undisturbed ground (Figures 6-8). These plots show a trend in ground disturbance re-vegetation as new burials age. Grave year series increase in average NDVI steadily from most recent and trend toward or past the control set average NDVI value (see 'Discussion' below for more about NDVI). Even disturbances where turf is scraped off and replaced are evident in the scatter plot, such as at Site 3 (Figure 8). The recovery trend at each site isn't perfectly chronological, particularly at Sites 1 and 3. In the former case (Figure 6), burial depth and the practice of tree planting have changed, and in the latter (Figure 8) where grave polygons are challenging to resolve due to meticulous turf scraping and replacement in grave digging. Site 2 (Figure 7) shows an apparent chronology of recovery, and by 2019 (two years old), many graves have recovered beyond the control site average NDVI value.

\subsection{Digital Terrain Models}

In addition to assessing slope of a study site, digital terrain models (DTM's) are robust ancillary datasets for multispectral imaging, and in some instances, can resolve subtleties in elevation that show grave locations where vegetative indices do not (Figures 4 and 5). Site 2 vegetative anomalies are detailed enough to delineate single graves from 2016. Even with a drone not equipped with RTK (real-time kinematics) or PPK (post-processing kinematics), and $Z$ error at Site 2 of $\pm 73 \mathrm{~cm}$, these five-year-old burials are evident. The addition of LiDar would improve such an additional proxy dataset. 


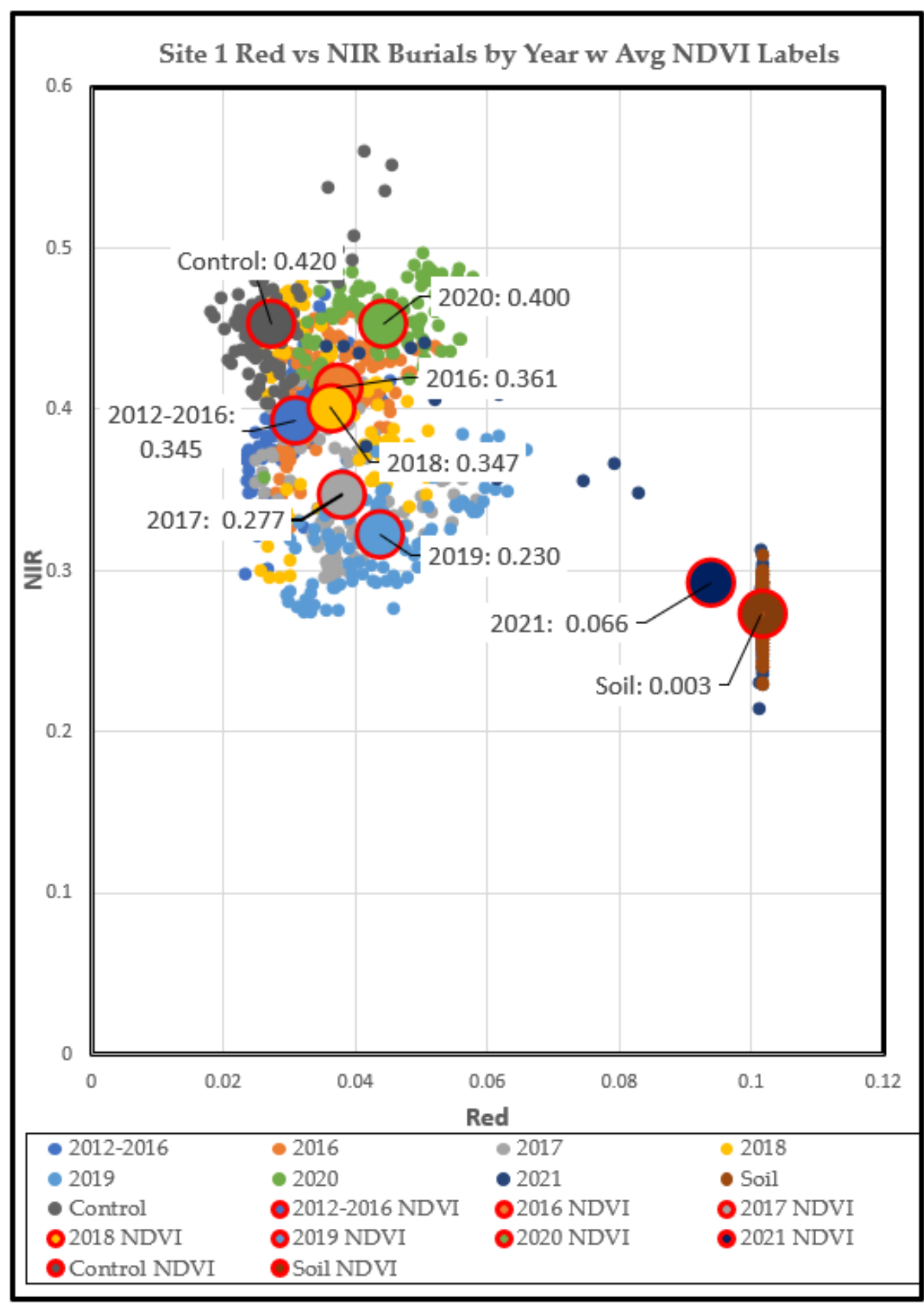

Figure 6. Site 1 Red vs. NIR scatterplot with average NDVI data labels for each series. NDVI increases from bottom right to top left. The oldest grave series, (2016), doesn't reach the same average NDVI value of the control set, indicating possible incomplete vegetation recovery. 
Site 2 Red vs NIR Burials by Year w Avg NDVI Labels

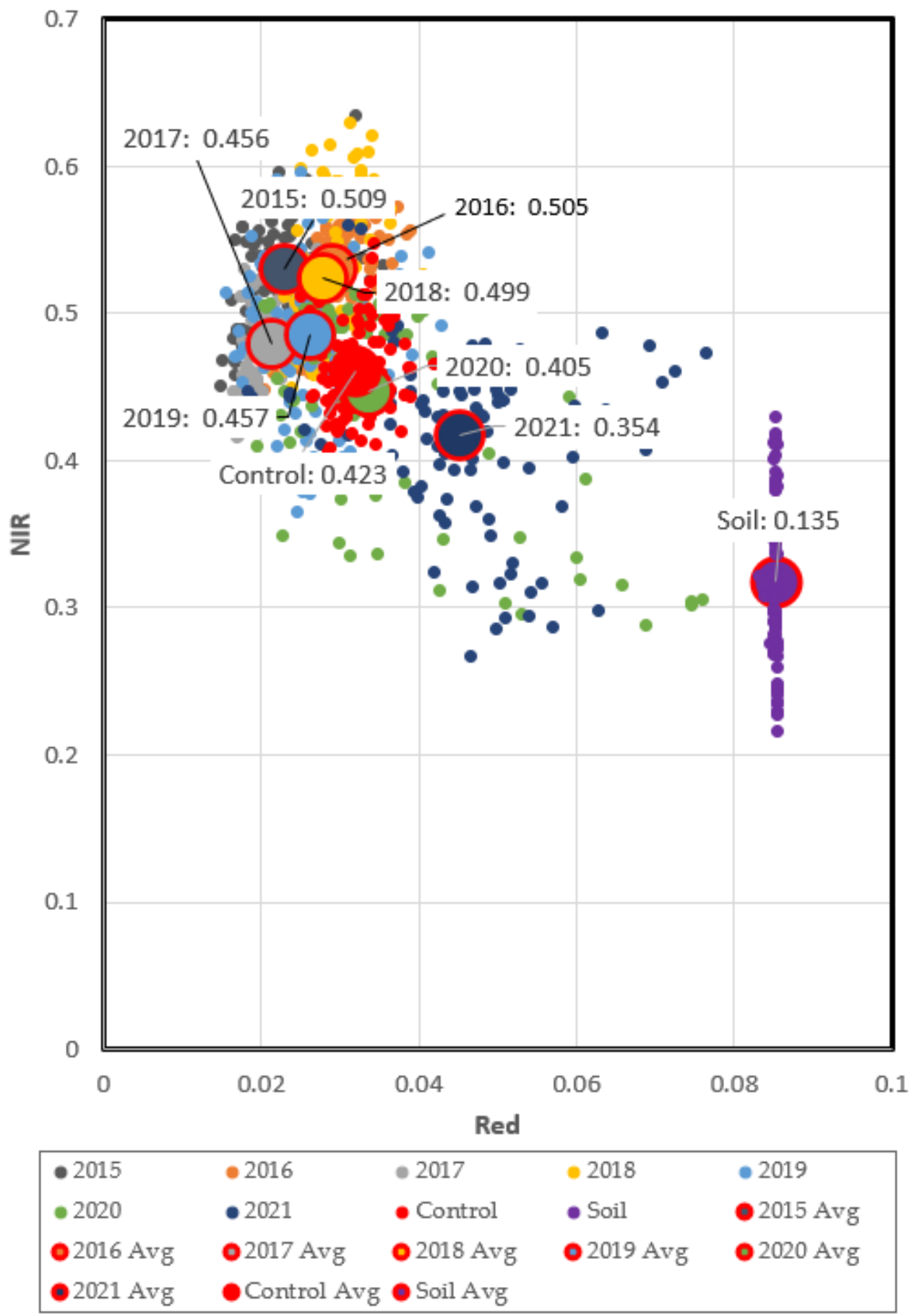

Figure 7. Site 2 Red vs. NIR scatterplot with average NDVI data labels for each series. NDVI increases from bottom right to top left. By 2019, average NDVI exceed that of the control set NDVI, indicating enhancement in vegetation from natural burials at this site. 
Site 3 Red vs. NIR Burials by Year w Avg NDVI Labels

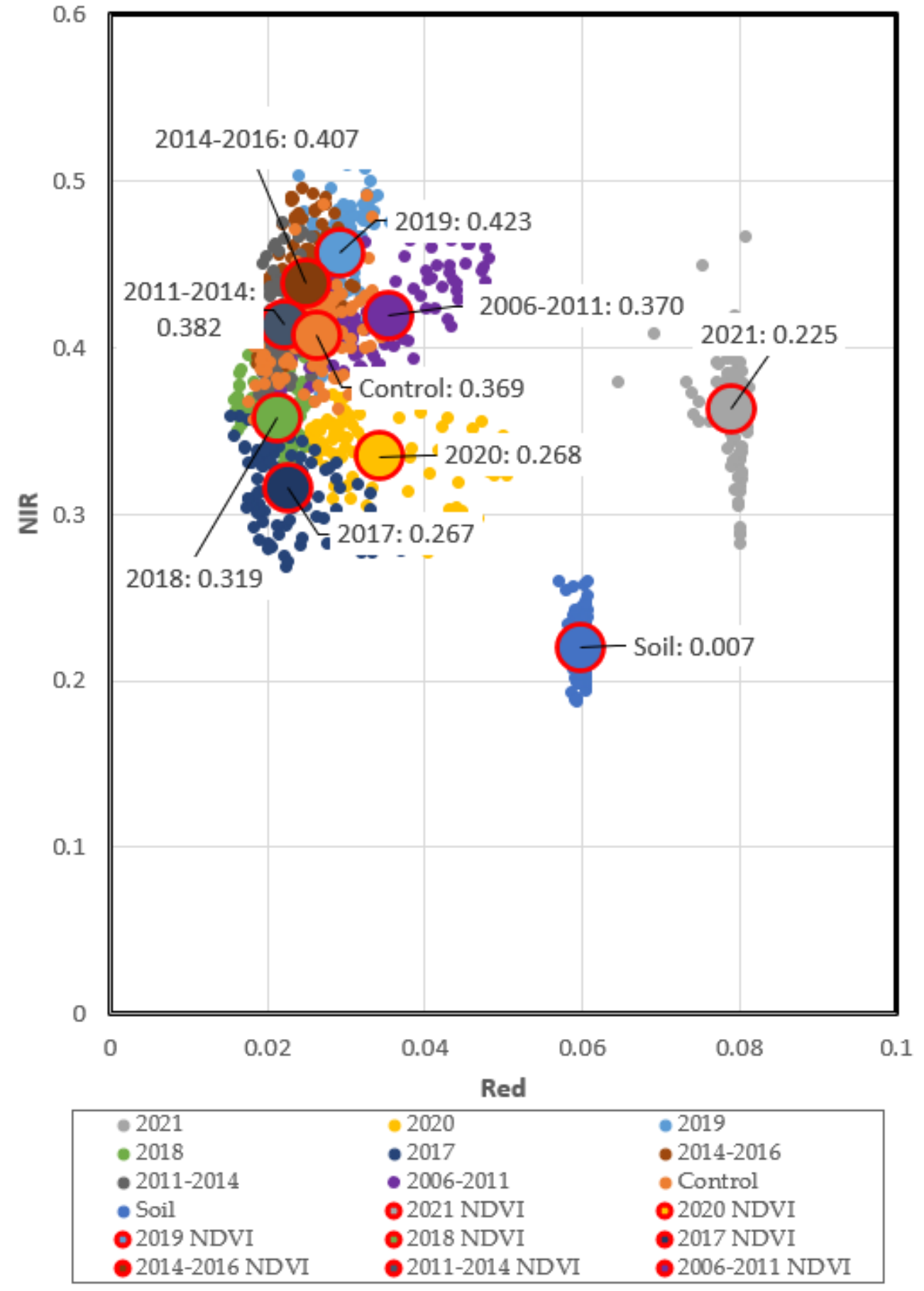

Figure 8. Site 3 Red vs. NIR scatterplot with average NDVI data labels for each series. NDVI increases from bottom right to top left. 2017 grave values reach the NDVI of the control set but show a slightly positive effect on vegetation from natural burials.

\subsection{Success of Imaging}

Using both vegetative indices and digital terrain modelling, $86 \%$ of 2021 single burials were successfully resolved at Site 1, while only $50 \%$ of burials were resolved at Site 3 from the same year (Table 2). NDVI and GNDVI show burials most clearly of the indices used in this study and show burials where orthomosaics (Figure 3) do not. See Figure 9 for NDVI, GNDVI, VARI, and NDRE comparisons at Site 1, and NDVI of each site in Figure 10. 
At each location, single burials were seen at Site 1 as far back as 2016; Site 2-2016, and Site 3-2017.

Table 2. Percent of detected graves by vegetation index or digital terrain model.

\begin{tabular}{|c|c|c|c|c|c|c|c|}
\hline & 2021 & 2020 & 2019 & 2018 & 2017 & 2016 & 2015 \\
\hline Site 1 & $86 \%$ & $62 \%$ & $61 \%$ & $49 \%$ & $48 \%$ & $23 \%$ & - \\
\hline Site 2 & $65 \%$ & $53 \%$ & $60 \%$ & $71 \%$ & $13 \%$ & $33 \%$ & $20 \%$ \\
\hline Site 3 & $50 \%$ & $30 \%$ & $26 \%$ & $9 \%$ & $3 \%$ & - & - \\
\hline
\end{tabular}

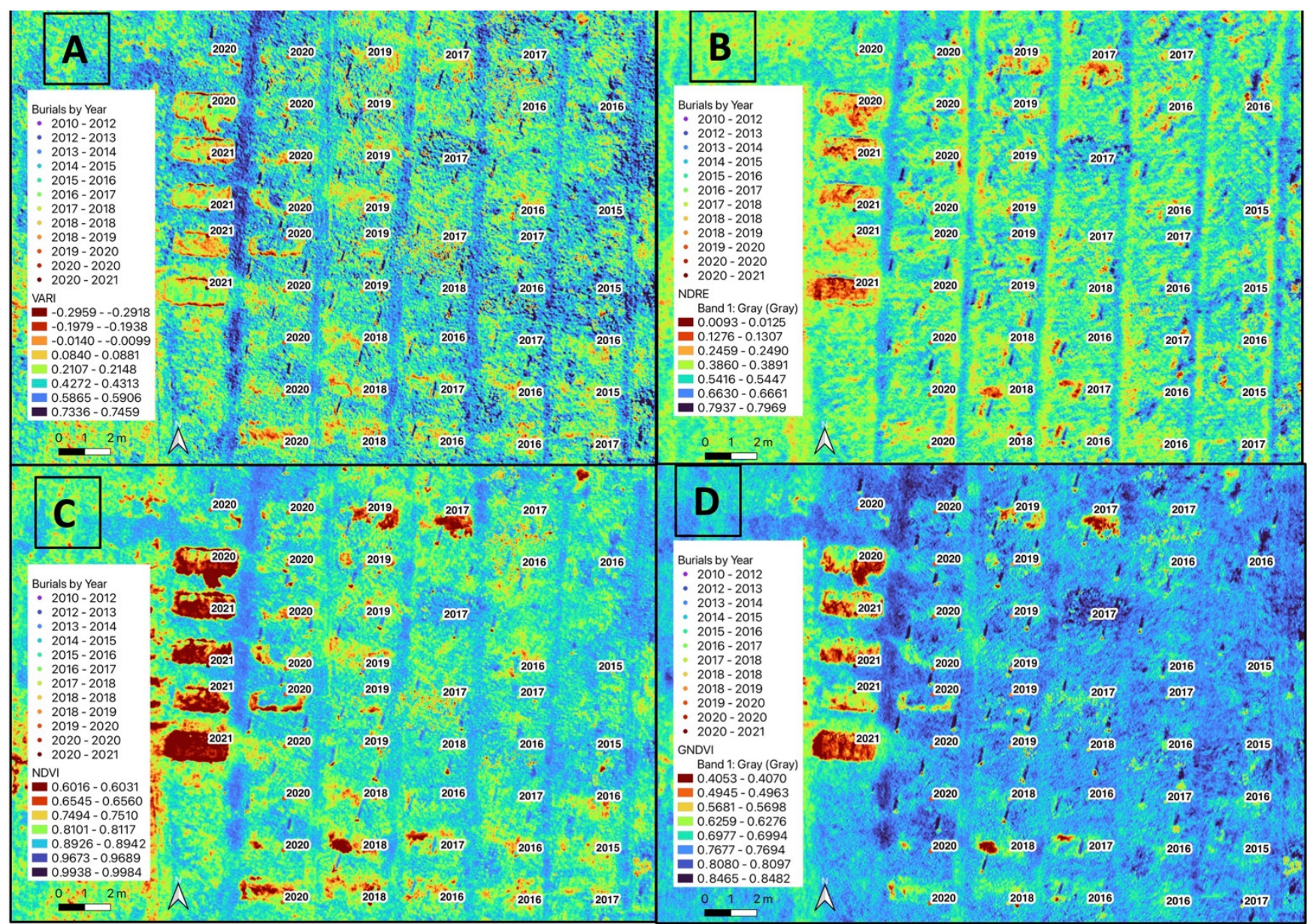

Figure 9. Site 1 Vegetative Index maps include VARI (A), NDRE (B), NDVI (C), and GNDVI (D). The full range of index values is constrained to highlight localised differences. NDVI shows single graves most clearly, with younger graves to the left (2021) and older graves to the right (2016). NDRE has the poorest single grave resolution. 

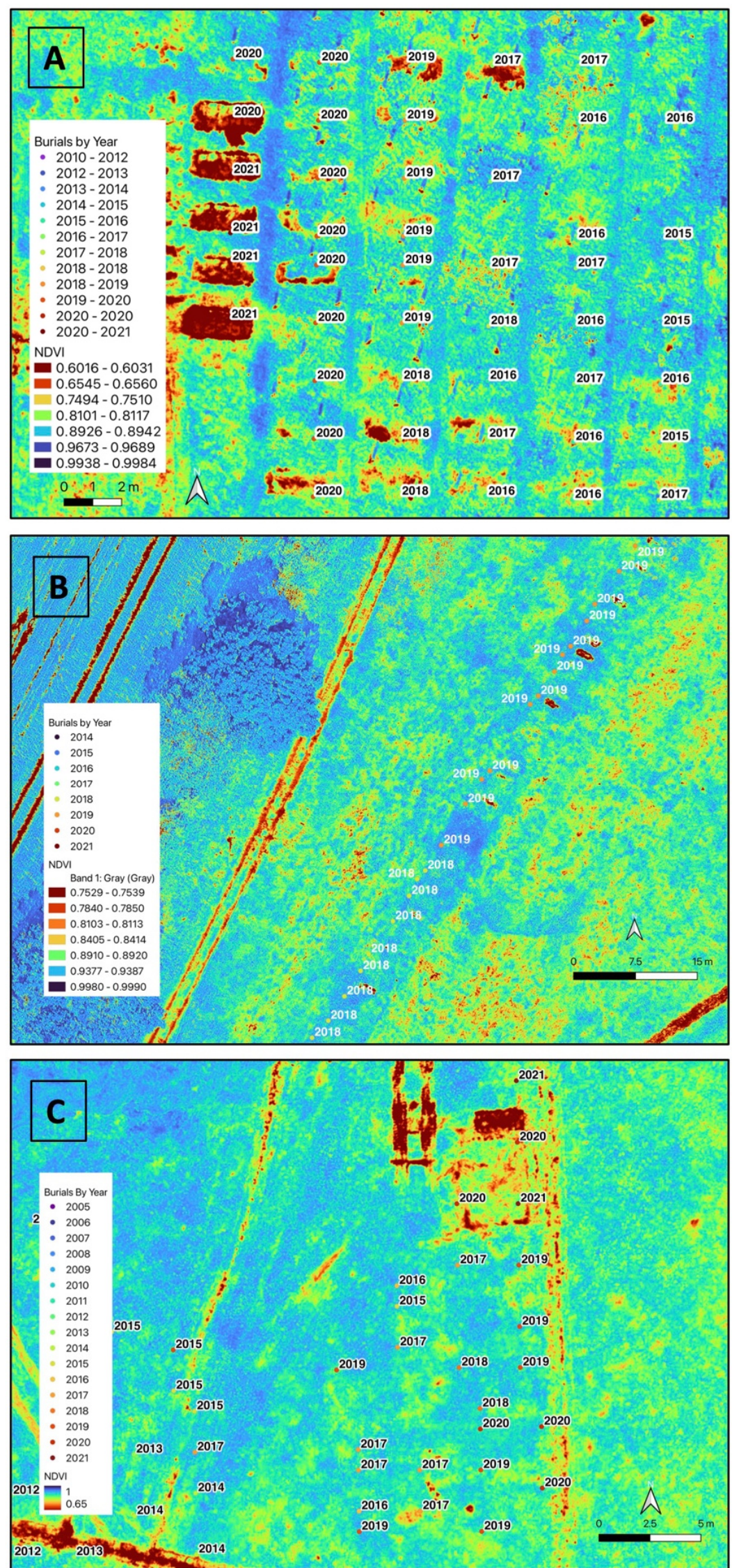

Figure 10. NDVI map of Sites 1 (A), 2 (B) and 3 (C) from top to bottom. The full range of index values is constrained to highlight localised differences. 


\section{Discussion}

GNDVI and NDVI maps showed burials more clearly than NDRE or VARI at each of the three sites (see Figure 9 for a comparison of vegetative indices at Site 1). GNDVI, NDVI, and NDRE use bands beyond visible light (in this case, RE and NIR). The sharp change in reflectance from vegetation between red and NIR bands is critical in determining plant health [17]. On the other hand, VARI uses low reflectance values and responds to more significant variations such as soil vs. vegetation [18]. In contrast, both NDVI and GNDVI focus more on green vs. dry biomass [18]. In both cases, multispectral cameras are required because of the need for red edge and near-infrared bands, which are typically filtered out by a Bayer Filter in consumer-grade cameras [19].

GNDVI is calculated similarly to NDVI but uses the green band instead of the red (see Appendix A) [11,18]. It indicates levels of photosynthetically absorbed radiation, making it more sensitive to chlorophyll than NDVI [20,21]. Figure 10 shows NDVI maps at each of the four sites, where all three sites appear to respond differently to human burials.

Site 1 shows a net loss in recovery per NDVI. The area of limited recovery in the southeast corner is also topographically-elevated, and lack of rain combined with multiple days over 20 degrees Celsius could be the reason for the drier biomass indicated by lower NDVI values relative to the control set at the oldest discernible graves (2016). Early burials were at a depth of $1.8 \mathrm{~m}$ and later changed to $1.4 \mathrm{~m}$. According to Mann et al. [22] (see also Statheropolous et al. [23]), burial depth can play a significant role in the rate of decomposition. Burials at up to $0.6 \mathrm{~m}$ may skeletonise in a few months to a year, while deeper burials even at $1.2 \mathrm{~m}$ take years [22], each dependant on soil and sub-soil type.

Site 2 appears to show human burials are a net gain for vegetative health at this site as the oldest discernible burials (2015) exceed the average NDVI value of the control set. Site 2 has a prominent impermeable clay layer at around one metre of depth. This site was flown a day after Site 1, thus also in dry conditions. Tumer et al. [24] show decomposition slows in clayey soils compared to loamy or organic soils, but clayey soils also have more microbial activity according to Pawlett et al. [25].

Site 3 appears to show a neutral or slightly positive gain in vegetative health from human burials. It was flown after several days of steady rain and cooler temperatures. Older discernible burials here (2017) are very close to the NDVI values of the control set. However, topography at this site is radically different from Sites 1 and 2 and slopes down to the south by 35 metres. This could impact drainage and thus moisture content and possible movement of decomposition by-products.

The difference in grave digging at all three sites impacts how these sites recover. Where graves are more compacted, decreased gas diffusion and anaerobic conditions slow decomposition [25]. Despite this, site vegetation may be invigorated by mechanical disturbance of the soil independent of human decomposition, such as decreased mechanical resistance to rooting [26].

Temperature is also a driving factor in decomposition. Mann et al. [22] say this is the most significant variable in human decomposition, but typically in unburied cadavers. However, Carter et al. [27] show moisture to be a more significant factor in decomposition. Variations in temperature combined with even slight changes in burial depth and moisture could create substantial differences in decomposition rates, which is in line with Vass et al. [28], who identity four variables of significance: temperature, moisture, $\mathrm{pH}$, and the partial pressure of oxygen. Some of these variables are unknown at the study sites presented here, but from available generic soil descriptions from the British Geological Survey Soil Observatory, only Site 3 is listed as having acidic soil [29].

Speed of decomposition is given emphasis here because the three study sites vary according to Vass et al.'s four significant variables [28]. Decomposition rate impacts vegetation health and can help explain why some sites over or under-recover. As a body decomposes, it initially kills off plant life because of the surge in nitrogen and phosphates released into the soil, according to Forbes et al. [30]. Following this die-off, the same nutrients can enhance vegetation growth. Pawlett et al. [25] advocate for shallow burial of 
less than $0.3 \mathrm{~m}$ to allow microbial activity to break down a corpse, promoting the recycling of nutrients in the soil. Deeper burials and soil with higher clay content reduce microbial activity and thus slow or prevent the release of nutrients. Pawlett's findings corroborate Forbes's supposition that at least in shallow graves, a surge of nutrients is released into the soil, but says this increase can enhance plant growth (Forbes and Pawlett's experiments varied considerably as their study sites were in Australia and the UK, respectively). In deeper burials, Pawlett demonstrates that the nutrient release is much slower at a $1 \mathrm{~m}$ burial depth [25].

Even minor differences between sites can change how bodies in natural burials decompose. The corpse/soil ecosystem can vary considerably in a similar climate and over small distances. Because of this, it is not unexpected to see differences in recovery at all three sites.

\section{Conclusions}

Observing long-term recovery trends and detection limits in multispectral imaging of a single human burial is yet to be published, and this work begins to fill that critical gap. Understanding the uses and limitations of this technology before a forensic search informs decision making for instances where multispectral remote sensing would be useful, and if so, how to acquire it.

These case studies only demonstrate recovery trends in one climate type (maritime, temperate) at one time of year. Further work is needed in different climates, soils, seasons, and burial depths, as these are all critical variables in how human decomposition interacts with soil and influences vegetation growth. In this way, multispectral drone imagery is akin to geophysical assessments of burials, especially over time [31]: there is no simple answer or single technique-all are constrained by the environment. But as limited as this study may be, the technology reaches into the remit of archaeology, ecology, forensics, and agriculture, to name a few. More specifically, the use of drone-aquired multispectral data may be added to the conjunctive use of other technologies (botany, pedology, geophysics, search dogs) advocated in the search for buried human remains [32].

Author Contributions: Conceptualization, B.R. and A.R.; methodology, B.R.; software, B.R.; validation, B.R. and A.R.; formal analysis, B.R.; investigation, B.R.; resources, B.R.; data curation, B.R.; writing-original draft preparation, B.R.; writing—review and editing, A.R.; visualization, B.R.; supervision, A.R.; project administration, A.R.; funding acquisition, B.R. All authors have read and agreed to the published version of the manuscript.

Funding: Partial funding for this project was provided by the Hugh Wisnom scholarship through Queen's University, Belfast. See https: / / pure.qub.ac.uk/en/prizes/hugh-wisnom-scholarship (accessed on 17 December 2021) for more information.

Institutional Review Board Statement: Research was conducted in accordance with ethics and standards of Queen's University, Belfast laid out here: https: / www.qub.ac.uk/Research/Governanceethics-and-integrity/Ethics/ (accessed on 18 December 2021).

Informed Consent Statement: Not applicable.

Data Availability Statement: Not applicable.

Acknowledgments: The author is indebted to site owners and managers for permission to fly these three sites. Many thanks to the site managers for their help in answering myriad questions. Thanks to Drone Deploy and Pix4D for providing an academic licence, and Sentera for providing an academic rate on the $6 x$ sensor.

Conflicts of Interest: The author declares no conflict of interest. The funders had no role in the design of the study; in the collection, analyses, or interpretation of data; in the writing of the manuscript, or in the decision to publish the results. 


\section{Appendix A}

Formulas below are used to calculate index products shown in Figures 5, 9 and 10, and NDVI values in scatterplots in Figures 6-8.

$$
\begin{gathered}
V A R I=\frac{\text { Green }- \text { Red }}{\text { Green }+ \text { Red }- \text { Blue }} \\
\text { NDRE }=\frac{\text { Red Edge }- \text { Red }}{\text { Red Edge }+ \text { Red }} \\
N D V I=\frac{N I R-\text { Red }}{\text { NIR }+ \text { Red }} \\
\text { GNDVI }=\frac{\text { NIR }- \text { Green }}{\text { NIR }+ \text { Green }}
\end{gathered}
$$

\section{References}

1. FAFG. Available online: https:// fafg.org/ (accessed on 9 December 2021).

2. Kalacska, M.; Bell, L.S. Remote Sensing as a Tool for the Detection of Clandestine Mass Graves. Can. Soc. Forensic Sci. J. 2006, 39, 1-13. [CrossRef]

3. Leblanc, G.; Kalacska, M.; Soffer, R. Detection of Single Graves by Airborne Hyperspectral Imaging. Forensic Sci. Int. 2014, 245, 17-23. [CrossRef] [PubMed]

4. Parrott, E.; Panter, H.; Morrissey, J.; Bezombes, F. A Low Cost Approach to Disturbed Soil Detection Using Low Altitude Digital Imagery from an Unmanned Aerial Vehicle. Drones 2019, 3, 50. [CrossRef]

5. Isaacks, M.E.R. The Use of Near-Infrared Remote Sensing in the Detection of Clandestine Human Remains (Unpublished Thesis). Master Thesis, Texas State University, San Marcos, Texas, USA, 2015.

6. Evers, R.; Masters, P. The Application of Low-Altitude near-Infrared Aerial Photography for Detecting Clandestine Burials Using a UAV and Low-Cost Unmodified Digital Camera. Forensic Sci. Int. 2018, 289, 408-418. [CrossRef] [PubMed]

7. Urbanová, P.; Jurda, M.; Vojtíšek, T.; Krajsa, J. Using Drone-Mounted Cameras for on-Site Body Documentation: 3D Mapping and Active Survey. Forensic Sci. Int. 2017, 281, 52-62. [CrossRef] [PubMed]

8. Butters, O.; Krosch, M.N.; Roberts, M.; MacGregor, D. Application of Forward-Looking Infrared (FLIR) Imaging from an Unmanned Aerial Platform in the Search for Decomposing Remains. J. Forensic Sci. 2021, 66, 347-355. [CrossRef] [PubMed]

9. Brabazon, H.; DeBruyn, J.M.; Lenaghan, S.C.; Li, F.; Mundorff, A.Z.; Steadman, D.W.; Stewart, C.N. Plants to Remotely Detect Human Decomposition? Trends Plant Sci. 2020, 25, 947-949. [CrossRef]

10. Murray, B.; Anderson, D.T.; Wescott, D.J.; Moorhead, R.; Anderson, M.F. Survey and Insights into Unmanned Aerial-Vehicle-Based Detection and Documentation of Clandestine Graves and Human Remains. Hum. Biol. 2018, 90, 45-61. [CrossRef]

11. Dozal, L.; Silván-Cárdenas, J.L.; Moctezuma, D.; Siordia, O.S.; Naredo, E. Evolutionary Approach for Detection of Buried Remains Using Hyperspectral Images. Photogramm. Eng. Remote Sens. 2018, 84, 435-450. [CrossRef]

12. Silván-Cárdenas, J.L.; Caccavari-Garza, A.; Quinto-Sánchez, M.E.; Coronado-Juárez, E.; Quiroz-Suarez, D. Assessing Optical Remote Sensing for Grave Detection. Forensic Sci. Int. 2021, 329, 111064. [CrossRef] [PubMed]

13. Rocke, B.; Ruffell, A.; Donnelly, L. Drone Aerial Imagery for the Simulation of a Neonate Burial Based on the Geoforensic Search Strategy (GSS). J. Forensic Sci. 2021, 66, 1506-1519. [CrossRef] [PubMed]

14. Bioucas-Dias, J.M.; Plaza, A.; Camps-Valls, G.; Scheunders, P.; Nasrabadi, N.; Chanussot, J. Hyperspectral Remote Sensing Data Analysis and Future Challenges. IEEE Geosci. Remote Sens. Mag. 2013, 1, 6-36. [CrossRef]

15. Making Successful Maps—DroneDeploy. Available online: https://help.dronedeploy.com/hc/en-us/articles/1500004964282Making-Successful-Maps (accessed on 10 December 2021).

16. Image Acquisition. Available online: https://support.pix4d.com/hc/en-us/articles/115002471546-Image-acquisition (accessed on 10 December 2021).

17. Jones, H.G.; Vaughan, R.A. Remote Sensing of Vegetation: Principles, Techniques, and Applications; OUP: Oxford, UK, 2010; ISBN 9780-19-920779-4.

18. Costa, L.; Nunes, L.; Ampatzidis, Y. A New Visible Band Index (VNDVI) for Estimating NDVI Values on RGB Images Utilizing Genetic Algorithms. Comput. Electron. Agric. 2020, 172, 105334. [CrossRef]

19. Park, W.; Pak, S.; Shim, H.; Le, H.A.N.; Im, M.; Chang, S.; Yu, J. Photometric Transformation from RGB Bayer Filter System to Johnson-Cousins BVR Filter System. Adv. Space Res. 2016, 57, 509-518. [CrossRef]

20. García Cárdenas, D.A.; Ramón Valencia, J.A.; Alzate Velásquez, D.F.; Palacios Gonzalez, J.R. Dynamics of the Indices NDVI and GNDVI in a Rice Growing in Its Reproduction Phase from Multi-Spectral Aerial Images Taken by Drones I SpringerLink. Available online: https:/ /link.springer.com/chapter/10.1007/978-3-030-04447-3_7 (accessed on 9 December 2021).

21. Candiago, S.; Remondino, F.; De Giglio, M.; Dubbini, M.; Gattelli, M. Evaluating Multispectral Images and Vegetation Indices for Precision Farming Applications from UAV Images. Remote Sens. 2015, 7, 4026-4047. [CrossRef] 
22. Mann, R.W.; Bass, W.M.; Meadows, L. Time since Death and Decomposition of the Human Body: Variables and Observations in Case and Experimental Field Studies. J. Forensic Sci. 1990, 35, 103-111. [CrossRef] [PubMed]

23. Statheropoulos, M.; Spiliopoulou, C.; Agapiou, A. A Study of Volatile Organic Compounds Evolved from the Decaying Human Body. Forensic Sci. Int. 2005, 153, 147-155. [CrossRef]

24. Tumer, A.R.; Karacaoglu, E.; Namli, A.; Keten, A.; Farasat, S.; Akcan, R.; Sert, O.; Odabaşi, A.B. Effects of Different Types of Soil on Decomposition: An Experimental Study. Leg. Med. 2013, 15, 149-156. [CrossRef] [PubMed]

25. Pawlett, M.; Rickson, J.; Niziolomski, J.; Churchill, S.; Kešner, M. Human Cadaver Burial Depth Affects Soil Microbial and Nutrient Status. Archaeol. Environ. Forensic Sci. 2018, 1, 119-125. [CrossRef]

26. Gojda, M.; Hejcman, M. Cropmarks in Main Field Crops Enable the Identification of a Wide Spectrum of Buried Features on Archaeological Sites in Central Europe. J. Archaeol. Sci. 2012, 39, 1655-1664. [CrossRef]

27. Carter, D.O.; Yellowlees, D.; Tibbett, M. Moisture Can Be the Dominant Environmental Parameter Governing Cadaver Decomposition in Soil. Forensic Sci. Int. 2010, 200, 60-66. [CrossRef] [PubMed]

28. Vass, A.A. The Elusive Universal Post-Mortem Interval Formula. Forensic Sci. Int. 2011, 204, 34-40. [CrossRef] [PubMed]

29. Soils Guide-Soilscapes. Available online: http://www.landis.org.uk/services/soilsguide/soilscapes.cfm?ssid=6 (accessed on 10 December 2021).

30. Deadly Secrets-The Science of Decomposition-Curious. Available online: https://www.science.org.au/curious/decomposition (accessed on 10 December 2021).

31. Pringle, J.K.; Jervis, J.; Cassella, J.P.; Cassidy, N.J. Time-Lapse Geophysical Investigations over a Simulated Urban Clandestine Grave. J. Forensic Sci. 2008, 53, 1405-1416. [CrossRef] [PubMed]

32. Donnelly, L.; Harrison, M.; Pirrie, D.; Ruffell, A.; Dawson, L. (Eds.) A Guide to Forensic Geology; Geological Society: London, UK, 2021. 